\title{
Kebijakan Lisensi Telekomunikasi
}

\author{
Sigit Haryadi
}

Institut Teknologi Bandung

Maret 2017

\section{Paper DOI 10.17605/OSF.IO/WP9C4}

Haryadi, S. (2018, March 1). Kebijakan Lisensi Telekomunikasi. Retrieved from osf.io/preprints/inarxiv/wp9c4

\begin{abstract}
Abstrak
Tulisan ini merupakan Catatan Kuliah atau Lecture Note "Ekonomi, Bisnis, Regulasi dan Kebijakan Telekomunikasi" yang menjelaskan teori dari the International Telecommunication Union tentang kebijakan lisensi bagi Provider dan Operator Telekomunikasi, yang dilengkapi dengan catatan tentang yang pernah terjadi di Indonesia dan analisisnya.
\end{abstract}

\section{Teori Dasar dari the International Telecommunication Union Tentang Lisensi Telekomunikasi}

\subsection{Definisi Lisensi Telekomunikasi}

a) Adalah kegiatan pemerintah memberikan otorisasi kepada suatu perusahaan untuk

- Memberikan layanan telekomunikasi, dimana perusahaan yang mendapatkan lisensi disebut Service Provider

- Mengoperasikan suatu jaringan dan fasilitas telekomunikasi, dimana perusahaan yang mendapatkan lisensi disebut Network Operator (di negara lain, ada yang menyebutkan sebagai "Carrier" atau "backbone operator")

- Memberikan layanan telekomunikasi sekaligus mengoperasikan jaringan telekomunikasi, di Indonesia disebut FNSP (Full Network Service Provider)

b) Mendefinisikan kondisi dan persyaratan dari suatu otorisasi, dan menjelaskan kewajiban dan hak network operator.

- Catatan: Di masa lalu, ketika masih ada monopoli, operator tidak mempunyai lisensi, lalu ketika ada new entrant yang mendapat lisensi, maka operator eksisting yang disebut sebagai incumbent operator otomatis diberikan lisensi.

- Incumbent FNSP di Indonesia, sebelum tahun 2000:

- Telkom (waktu itu masih $100 \%$ milik negara) melayani telekomunikasi dalam negeri 
- Indosat (waktu itu masih $100 \%$ milik negara) melayani telekomunikasi luar negeri

- Tahun 2005 (ketika Telkom dan Indosat sudah diprivatisasi): Telkom dan Indosat boleh melayani telekomunikasi dalam dan luar negeri.

c) Lisensi adalah sangat penting dalam konteks menjalankan transisi ekonomi: contohnya di negara-negara Amerika Latin, ketika operator telekomunikasi diprivatisasi, maka kondisinya sama dengan memberikan concessions atau franchises kepada new entrant

d) Contoh di atas tidak terjadi di negara - negara yang sejak lama sudah melakukan privatisasi terhadap operator telekomunikasi, misalkan di US dan Canada

e) Di beberapa negara tidak digunakan istilah "license", melainkan digunakan istilah "concession" dan "franchise"

f) Proses pemberian lisensi telekomunikasi

- Ada negara yang dilakukan oleh regulator independent

- Jika regulator independent belum ada, maka pemberian lisensi dilakukan oleh Menteri. (Misal di Indonesia)

g) Kegiatan pemberian lisensi seharusnya

- Merupakan kegiatan integral untuk meretruksturisasi industri telekomunikasi dalam negeri

- Menentukan jumlah dan jenis operator

- Mengatur kompetisi yang adil diantara operator

- Usaha pemerintah menerima pendapatan dari pajak maupun non pajak ( di Indonesia disebut PNBP)

- Mengatur efisiensi jaringan telekomunikasi

\subsection{Tujuan Pemberian Lisensi Telekomunikasi:}

\section{1) Mengatur Ketentuan Layanan Publik yang Penting}

Perlu dicatat bahwa layanan internet di beberapa negara telah ditetapkan menjadi Hak Asasi Manusia.

2) Dilakukan dalam rangka memperluas jaringan dan layanan telekomunikasi di suatu negara

Di beberapa negara, perusahaan yang mendapat lisensi telekomunikasi diwajibkan membangun jaringan dengan coverage $100 \%$, dan jika persyaratan lisensi ini tidak dipenuhi, perusahaan akan didenda atau dicabut lisensinya.

3) Dalam rangka memprivatisasi dan mengkomersialkan telekomunikasi 
Pada masa lalu (sebelum tahun 1980'an, layanan telekomunikasi di hampir semua negara di dunia, kecuali US, Canada dan UK, adalah merupakan "cost centre” yaitu merupakan usaha rugi, sehingga perusahaan telekomunikasi harus disubsidi oleh pemerintah, tetapi sejak tahun 1980an layanan telekomunikasi tidak lagi merupakan "cost centre", tetapi sudah merupakan usaha yang menguntungkan, maka pemberian lisensi telekomunikasi dilakukan untuk privatisasi dan komersialisasi layanan dan jaringan telekomunikasi

4) Untuk meregulasi struktur pasar telekomunikasi.

Terkait hal ini di beberapa negara telah dilakukan pembatasan jumlah operator telekomunikasi.

5) Membangun kerangka Kompetisi yang Sehat.

Pemerintah atau regulator harus melakukan usaha-usaha untuk menjamin kehidupan semua perusahaan yang diberi lisensi telekomunikasi agar mendapat keuntungan yang wajar dalam rangka membangun keberlangsungan layanan telekomunikasi di negaranya

6) Mengalokasikan Sumberdaya Yang langka, yaitu spectrum Frekuensi dan Access to rights of way

Usaha untuk mendapatkan Revenue pemerintah. Misalnya dilakukan dengan cara memberikan ketentuan Annual license fees dan di Indonesia disebut PNBP (Penerimaan Negara Bukan Pajak) yang terdiri dari BHP (Biaya Hak Penggunaan) Spektrum Frekuensi, BHP Penyelenggaraan Telekomunikasi, dan Kewajiban Pelayanan Universal (USO = Universal Service Obligation)

7) Dalam rangka memberikan consumer Protection.

Biasanya berupa: price regulation, billing practices, consumer complaint mechanisms, dispute resolution, limitations of liability for service defaults, Mandatory services to consumers (misal: directory services, operator assistance dan emergency services).

8) Memberikan Kepastian Hukum.

Menurut ITU-D, ini merupakan factor kritis dalam proses pemberian lisensi, yang dilakukan dengan memberikan suatu clearly defining the rights and obligations kepada operator, umumnya regulator atau pemerintah tidak mampu menjalankan fungsi ini, bila investasi asing terlalu besar pada sector telekomunikasi. 


\subsection{Multilateral Trade Rules}

The General Agreement on Trade in Services (GATS) dan WTO Agreement on Basic Telecommunications (ABT) of the World Trade Organization (WTO) mencakup pengaturan pemberian lisensi negara yang ikut menandatangani dalam hal pemberian lisensi telekomunikasi

- (i) General GATS Requirements: Semua anggota WTO menyatakan mengikuti "general obligations and disciplines" yang diatur oleh GATS, yang punya akibat langsung pada proses pemberian lisensi telekomunikasi, yaitu.

- (a) Most Favored Nation (MFN) Treatment (GATS Article II) - Suatu negara tidak boleh "mengistimewakan" suatu negara lain.

- (b)Transparency (GATS Article III) - Semua aturan terkait lisensi telekomunikasi harus dipublikasikan secara terbuka

- ( c)Barriers to Trade (GATS Article VI) - Tidak boleh "constitute unnecessary barriers to trade".

\section{- (ii) Specific ABT Commitments}

- Aturan khusus mengenai layanan telekomunikasi dasar, dahulu adalah layanan telepon, sekarang adalah layanan internet.

- Komitmen pada WTO Agreement on Basic Telecommunications require many countries untuk membuka akses lebih besar bagi market dunia.

- Negara - negara yang menandatangani "The WTO Regulation Reference Paper" mengikat mereka untuk mengadopsi beberapa praktik peraturan yang berlaku untuk layanan telekomunikasi dasar.

\subsection{Jenis- jenis Pemberian Lisensi Telekomunikasi di Dunia}

Ada tiga pendekatan:

- 1. Hanya satu operator yang mendapat lisensi.

- 2. Otorisasi Umum kepada penyelenggara jaringan telekomunikasi

- 3. Tidak ada satupun Lisensi yang diberikan, jadi bersifat open entry.

Situasi di Amerika Utara (US dan Canada) adalah BERBEDA, karena tidak ada lisensi untuk operator telekomunikasi, kecuali lisensi spektrum(FCC Section 214), CRTC international 
service licences, and public convenience and necessity certificates in some states and provinces.

\subsection{Proses Pemberian Lisensi}

Ada Lima tipe proses lisensi:

1. Pemberian lisensi hanya kepada operator incumbent yang memonopoli jaringan dan layanan telekomunikasi.

Dimungkinkan dilakukan di negara-negara yang relative kecil (wilayah sempit dan penduduknya sedikit)

\section{Pemberian lisensi kepada New Entrants}

Bila operator incumbent tidak mau meneruskan bisnisnya, atau dinilai pemerintah atau regulator tidak pantas menjadi operator telekomunikasi lagi

\section{Lisensi kepada incumbent maupun ke New Entrants}

Ini terjadi pada umumnya di sebagian besar negara - negara di dunia, dimana sebelumnya hanya ada satu operator monopoli.

\section{Otorisasi Umum}

Umumnya hanya dilakukan untuk operasional dari service provider yang tidak memiliki jaringan telekomunikasi sendiri.

\section{Lelang, atau lotere dan/atau Comparative Evaluation Processes terhadap}

\section{Spectrum}

Pilihan yang bebas diberikan kepada setiap negara. Lotere dilakukan bila peserta lelang semuanya dinilai layak dan mampu mendapatkan lisensi, dan pemerintah tidak ingin mendapatkan pendapatan negara yang besar dari proses lelang. Lelang dilakukan bila pemerintah berharap ada peserta lelang yang menawar harga yang tinggi. Comparative Evaluation Processes, dilakukan bila regulator atau pemerintah tidak punya keyakinan kepada semua calon peserta lelang, sebelum melakukan penilaian terhadap proposal teknis dari peserta lelang, dan lalu mengkombinasikan nilai proposal dan nilai dari tinggi rendahnya tawaran harga dari peserta lelang.

\subsection{Konsesi, BOT dan lain sebagainya}

- Pengertian konsesi di beberapa negara adalah berbeda-beda:

- Di Mexico, istilah konsesi adalah mengacu pada dokumen lisensi yang merupakan perjanjian komersial antara pemerintah dengan operator. 
- Di Asia, konsesi adalah semacam perjanjian joint venture, yang tidak memberikan garansi full licenses untuk mengoperasikan jaringan telekomunikasi secara independent.

- Ada beberapa jenis "joint ventures" antara investor swasta dengan pemerintah atau operator monopoli, yaitu: Build-Operate-Transfer (BOT), Build- Transfer-Operate (BTO), Build-Operate-Own (BOO). Ada beberapa contoh implementasinya::

- > BTO: Thailand, Philippines

- $>$ BOT: Lebanon, India, Indonesia (disebut Kerja Sama Operasi)

- > BOO: Malaysia, Solomon Islands

\section{- $\quad$ Service Areas}

Ada beberapa negara yang memberikan lisensi telekomunikasi bersifat local atau pada suatu wilayah tertentu saja, tapi ada juga yang memberikan lisensi secara nasional.

\subsection{Konten Lisensi}

Beberapa hal yang mungkin dimasukkan pada konten lisensi antara lain:

- Lisensi untuk mengoperasikan jaringan telekomunikasi

- Lisensi spectrum frekuensi

- Kondisi umum lisensi: Kelayakan, aplikasi, kepemilikan, fasilitas \& peralatan, catatan \& laporan, kerja sama dengan regulator, kerjasama dengan otoritas pemerintah lainnya, akses terhadap jalan yang baik dan menyeluruh.

- Ketentuan spesifik untuk lisensi: penggunaan spektrum radio, penomoran, direktori \& layanan darurat, kewajiban akses \& layanan universal, QoS, Keamanan

- Hubungan dengan pelanggan: syarat \& kondisi pelayanan, keluhan pelanggan, perlindungan pelanggan, regulasi harga, penyelesaian perselisihan

- Hubungan dengan operator lisensi lainnya (OLO = Other License Operator): Interkoneksi, praktik anti persaingan, akses terhadap fasilitas berbagi, penyelesaian perselisihan

- Amandemen, Pembaharuan \& Penghentian: amandemen oleh regulator, amandemen oleh kesepakatan bersama, perpanjangan, penghentian karena, penghentian tidak ada pembaharuan

\section{Daftar Sebagian Lisensi Telekomunikasi Indonesia}

1. Penyelenggaraan Jaringan Telekomunikasi. 
2. Penyelenggaraan Jaringan Tetap Lokal Tanpa kabel dengan Mobilitas Terbatas. (FWA)

3. Penyelenggara Sarana Transmisi Telekomunikasi Internasional melalui Sistem Komunikasi Kabel Laut.

4. Penyelenggara Jaringan Tetap (Jartap)
a. Penyelenggaraan Jaringan Tetap Lokal
b. Jaringan Tetap Sambungan Langsung Jarak Jauh
c. Jaringan Tetap Internasional
d. Jaringan Tetap Tertutup Berbasis Kabel (Jartup)

5. Penyelenggara Jasa Telekomunikasi

a. Penyelenggaraan Jasa Internet Teleponi Untuk Keperluan Publik

b. Penyelenggaraan Warung Telekomunikasi

c. Penggunaan Fitur Berbayar Jasa Telekomunikasi

d. Penyelenggaraan Jasa Pesan Premium Dan Pengiriman Jasa Pesan Singkat Ke Banyak Tujuan

6. Penyelenggara Layanan Televisi Protokol Internet (Internet Protocol Television / IPTV) Di Indonesia

7. Penyelenggara Telekomunikasi Khusus Untuk Keperluan Instansi Pemerintah dan Badan Hukum

8. Penyediaan Infratruktur dan/atau Ekosistem dari Kewajiban Pelayanan Universal Telekomunikasi

9. Penyediaan Sistem Informasi Manajemen Dan Monitoring Layanan Internet Kecamatan

10. Penyediaan Nusantara Internet Exchange Untuk Layanan Internet Pada Wilayah Pelayanan Universal Telekomunikasi Internet Kecamatan

11. Penyelenggara Jaringan Bergerak Selular Generasi Ketiga Dengan Cakupan Nasional

12. Penggunaan Pita Frekuensi Radio $2,1 \mathrm{GHz}$ Untuk Penyelenggaraan Jaringan Bergerak Seluler

13. Penyelenggara Telekomunikasi Yang Menggunakan Satelit

14. Penggunaan Bersama Menara Telekomunikasi

15. Penyelenggara Jasa Bidang Pos

16. Penyelenggara Jasa Internet / ISP (Internet service Provider)

17. Penyeleggara jaringan / NAP (Network Access Point) 
18. Penyelenggara Radio Trunking

19. Penyelenggara Siaran TV tidak berbayar (free TV)

20. Penyelenggara Siaran TV berbayar (pay TV)

21. Penyelenggara Radio Siaran

22. Penyelenggara Jaringan Bergerak Selular Generasi Keempat / LTE

23. Penyelenggara Multiplekser Televisi Digital

24. Dan lain-lain sebagainya.

Analisis (kondisi sampai akhir 2017): Kominfo harus segera menyelesaikan problem regulasi yang diakibatkan keputusan Mahkamah Konstitusi yang menetapkan hanya bahwa Keputusan Menteri, Keputusan Direktur Jenderal dan Keputusan Direktur hanya berlaku internal, padahal banyak regulasi terkait standar perangkat telekomunikasi di Indonesia yang dulu pernah ditetapkan dengan cara seperti itu sebenarnya masih sangat dibutuhkan bagi masyarakat pengguna maupun vendor sebagai payung hukum.

\section{Permasalahan Lisensi pada era Konvergensi di Indonesia}

Di sebagian besar negara - negara berkembang, termasuk Indonesia, lisensi pada era konvergensi jaringan dan layanan telekomunikasi menjadi permasalahan yang sangat rumit dan tidak terpecahkan, yang disebabkan oleh produk regulasi masa lalu, yang memisahkan lisensi penyelenggara telekomunikasi di satu sisi dengan penyelenggara siaran di sisi lain, padahal pada era konvergensi, satu jaringan telekomunikasi bisa memuat sekaligus layanan telekomunikasi dan layanan siaran.

\subsection{Permasalahan Teknologi di Era Konvergensi}

- Di masa lalu operator jaringan telekomunikasi publik hanya memuat layanan telekomunikasi (telepon \& pesan), di pihak lain jaringan penyiaran publik juga hanya memuat layanan siaran (radio \& televisi).

- Di era konvergensi:

a. Jaringan telekomunikasi publik bisa memuat convergence service, yaitu layanan telekomunikasi sekaligus layanan penyiaran

b. Jaringan penyiaran publik masih tetap hanya memuat siaran saja.

\subsection{Permasalahan Ownership di Indonesia}

- Operator jaringan dan layanan telekomunikasi dominan dimiliki asing.

- Operator jaringan dan layanan penyiaran dominan dikuasai pengusaha nasional 


\subsection{Penerimaan Negara}

Penerimaaan Negara dari pajak dan non-pajak (PNBP): Pajak yang didapat negara dari penyelenggaraan telekomunikasi adalah jauh lebih besar dibandingkan yang didapat dari penyelenggaraan penyiaran

\subsection{Asal dari Revenue penyelenggara telekomunikasi}

I. Di masa lalu:

a) Service Provider (= penyelenggara jastel / jasa layanan telekomunikasi) secara langsung mendapatkan revenue dari customernya.

b) Network Operator (=Penyelenggara jaringan telekomunikasi) mendapatkan revenue secara langsung dari customernya atau tidak langsung melalui service provider yang menyewa jaringannya.

c) FNSP: Service Provider \& Network Operator masih mendapatkan revenue seperti di era masa lalu, tetapi pendapatan operator menurun karena adanya service provider yang bisa memberikan layanan kepada publik tanpa membayar sewa jaringan (= OTT = over the top service provider)

II. Masa yang Akan datang

a) Terbuka kemungkinan kerjasama antara FNSP dengan provider OTT menggunakan hubber

b) Terbuka kemungkinan kerjasama antara FNSP telekomunikasi dengan Provider Penyiaran untuk memberikan layanan konvergen

\subsection{Revenue penyelenggara penyiaran}

I. Di masa lalu:

1. Content provider: mendapatkan revenue dari Penyelenggara Penyiaran

a) Penyelenggara penyiaran semuanya merangkap sebagai service provider sekaligus operator jaringan, terdiri dari

b) Siaran tidak berbayar: revenue dari iklan atau subsidi

c) Siaran berbayar (pay-tv) mendapatkan revenue dari customer + iklan

II. Di masa sekarang, kombinasi dari

a) Revenue masih diperoleh seperti masa lalu 
b) Terbuka peluang sekaligus ancaman pada era konvergen. Menjadi peluang jika regulasi konvergen mengharuskan kerjasama antara network operator dengan operator penyiaran.

c) Pada sistem siaran digital terestrial, ada dua kemungkinan

i. Bila mengadopsi sistem Jepang: tidak ada perubahan dibanding era tv analog

ii. Bila mengadopsi sistem Eropa, akan ada pemisahan antara

1.Operator yang memiliki perangkat multiplekser

2.Operator yang memiliki menara dan stasiun pemancar televisi

\subsection{Alternatif Solusi Regulasi Konvergensi}

- Sampai saat bahan kuliah ini dibuat, masih belum ada solusi mengenai regulasi konvergensi

- Harus mempertimbangkan banyak faktor, utamanya 5 faktor di atas.

- Kesepakatannya adalah regulasinya harus berbentuk Undang-Undang, tetapi isinya seperti apa, masih menjadi perdebatan.

- Selama belum dibuat Undang-Undang, ternyata sudah ada beberapa perusahaan yang membangun jaringan yang memberikan layanan konvergen (telekomunikasi/internet dan TV siaran).

\section{Soal-soal}

\section{TUGAS 1}

Kerjakan soal dengan mengacu regulasi yang masih berlaku di Indonesia:

- Hitunglah BHP penyelenggara jaringan dan jasa telekomunikasi yang memiliki Pendapatan kotor sebesar 1 triliun setahun

- Hitunglah Kewajiban Pelayanan Universal (KPU) penyelenggara jaringan dan jasa telekomunikasi yang memiliki Pendapatan kotor sebesar 1 triliun setahun

- Hitunglah BHP spektrum frekuensi dari salah satu operator seluler di Indonesia http://www.ditfrek.postel.go.id/elicensing/tools/simulasi/

2.

- Bagaimana cara/rumus menghitung biaya KPU (Kewajiban Pelayanan Universal)= USO (Universal Service Obligation) (jawab $=0,75 \%$ x Pendapatan kotor penyelenggara jastel) 
- Berapa realisasi PNBP sektor telekomunikasi pada tahun 2017? Dibandingkan dengan PDB sektor telekomunikasi, berapa persenkah PNBP nya?

- Berapa pendapatan kotor penyelenggara jaringan dan jasa telekomunikasi (total tahun 2017).

- D. Berapa target dan realisasi PNBP sektor telekomunikasi pada tahun 2017?

3. Mention each one example of a telecommunications policy concerning the respective objective: (i)Regulating Provision of an Essential Public Services, (ii)Expansion of networks and services and other universal service, (iii)Privatization, (iv)Regulating market structure, (v)Establishing a competition framework, (vi)Allocation of scarce resources, (vii)Generating Government Revenues, (viii)Consumer Protection, (ix)Regulatory certainty

\section{References}

[1] Homepage of The International Telecommunication Union: https://www.itu.int/en/Pages/default.aspx

[2] Link "Regulasi" dari Direktorat Jenderal Sumber Daya dan Perangkat Pos dan Informatika, Indonesia di: http://www.postel.go.id/

[3] Denny Setiawan. (2018). Regulasi dan kebijakan Telekomunikasi di Indonesia. Available di http://denysetia.wordpress.com/regulasi-spektrum-frekuensi-radioindonesia/regulasi-spektrum-frekuensi-radio-di-indonesia/kajian-kebijakan-danregulasi-frekuensi/

[4] Haryadi, S. (2018, February 28). Ikhtisar Organisasi Regulasi Telekomunikasi. Retrieved from osf.io/preprints/inarxiv/g9m3k

[5] Haryadi, Sigit. "Prinsip - Prinsip Penyusunan Kebijakan Negara Di Bidang Telekomunikasi." Open Science Framework, 22 Jan. 2018. Web. https://osf.io/32g65/

[6] Haryadi, S. (2018, January 29). Bab 4 dari buku "Ekonomi Bisnis Regulasi dan Kebijakan Telekomunikasi”: Prinsip - Prinsip Ilmu Ekonomi \& Perbankan. Retrieved from https://osf.io/az9ye

[7] Haryadi, S. (2018, January 19). Catatan Kuliah Ekonomi, Bisnis, Regulasi dan Kebijakan Telekomunikasi Bab 2 semester 2 Tahun 2017/2018: Prinsip-Prinsip Ilmu Hukum. Retrieved from https://osf.io/3c9n4

[8] Haryadi, S. (2018, January 17). Bab 1. Tren Global Pada Bisnis \& Teknologi Telekomunikasi. Retrieved from https://osf.io/fvcha

[9] Haryadi, S. (2018, February 1). Kalkulator Untuk Mengukur Tingkat Kompetisi di suatu Industri, dengan menggunakan rumus Indeks Haryadi. Retrieved from osf.io/fy $7 \mathrm{zu}$

[10] Haryadi, S. (2018, February 7). Statistik Terapan: Pengujian Regulasi \& Kebijakan Telekomunikasi. Retrieved from osf.io/3pkfw

[11] Sigit Haryadi. (2018, February). Applied Statistics for Assessment of the Regulation and Policy: case study in Telecommunication Industry.

DOI10.13140/RG.2.2.15774.02884 
[12] Windi Rahma Agustin; Sigit Haryadi. (2017). Sustainability of Indonesian Telecommunication Operators in the Era of Net Neutrality. 3rd International Conference on Wireless and Telematics (ICWT), July 2017 in Palembang, Indonesia.

[13] Sigit Haryadi. (2017). Chapter 9 Universal Access and Services Regulation Telecommunication Economy, Business, Regulations and Policy". Researchgate. DOI10.13140/RG.2.2.31572.60804

[14] Sigit Haryadi. (2017). Chapter 10 Introduction to Frequency Management Ekonomi Bisnis Regulasi dan Kebijakan Telekomunikasi. Researchgate.

DOI10.13140/RG.2.2.24861.72169.

[15] Sigit Haryadi. (2017). Catatan Kuliah Lisensi Provider dan Operator Telekomunikasi. DOI10.13140/RG.2.2.13117.67046.

[16] Sigit Haryadi. (2017). Catatan Kuliah "Overview Organisasi Regulasi Telekomunikasi". DOI10.13140/RG.2.2.34928.05122.

[17] Sigit Haryadi. (2017). Lecture Note "Telecommunication Interconnection". DOI10.13140/RG.2.2.21506.2784.

[18] Haryadi, S. (2017). Internet Services Pricing Regulation. Researchgate. DOI10.13140/RG.2.2.28217.16487.

[19] Haryadi, S. (2017). Catatan Kuliah Ekonomi Bisnis Regulasi dan Kebijakan Telekomunikasi : Prinsip - Prinsip Ilmu Ekonomi \& Perbankan. Researchgate. DOI10.13140/RG.2.2.29894.88648.

[20] Haryadi, S. (2017). Tren Global pada Bisnis \& Teknologi Telekomunikasi. DOI10.13140/RG.2.2.27168.58883.

[21] Haryadi, S. (2017). Ekonomi Bisnis Regulasi dan Kebijakan Telekomunikasi: Prinsip-Prinsip Ilmu Hukum. DOI10.13140/RG.2.2.30524.03207.

[22] Haryadi, S. (2017). Ekonomi Bisnis Regulasi dan Kebijakan Telekomunikasi: Prinsip-Prinsip Ilmu Hukum. DOI10.13140/RG.2.2.30524.03207.

[23] Haryadi, S. (2017). Ekonomi Bisnis Regulasi dan Kebijakan Telekomunikasi: Prinsip Penyusunan Kebijakan Negara. DOI10.13140/RG.2.2.17102.25927.

[24] Westi Riani; Sigit Haryadi. (2017). the Method of Tax Rate Determination Based On Fairness. Prosiding Seminar Nasional SNaPP2017, Bandung, Indonesia.

[25] Westi Riani; Sigit Haryadi. (2017). CALCULATOR for the Government to make the Fair Policy of Tax Rates. Researchgate. DOI10.13140/RG.2.2.18550.50246.

[26] Sigit Haryadi; Angelia Hermawan. (2014). Recommendations for handling price war between telecom operators in Indonesia. The 8th International Conference on Telecommunication Systems, Services, and Applications (TSSA), Indonesia.

[27] Sigit Haryadi; Febrianty. (2014). Recommendation on domestic Internet interconnection towards all-IP network. The 8th International Conference on Telecommunication Systems, Services, and Applications (TSSA), Indonesia.

[28] Sigit Haryadi; FestyLalita Niramaya. (2014). Study of unfair competition between regulated and unregulated VoIP providers in the mixed of non and all-IP network era. The 8th International Conference on Telecommunication Systems, Services, and Applications (TSSA), Indonesia. 